\title{
Nailing the Peak: City-Scale, Building-Specific Load Factor and Contribution to a Utility's Hour of Critical Generation
}

\author{
Joshua R. New ${ }^{1,2, *}$, Mark B. Adams ${ }^{1}$, Eric Garrison ${ }^{2}$, \\ William Copeland ${ }^{3}$, Brian Smith $^{3}$, and Andy Campbell ${ }^{3}$ \\ ${ }^{1}$ Oak Ridge National Laboratory, Oak Ridge, TN, U.S.A. \\ ${ }^{2}$ The University of Tennessee, Knoxville, TN, U.S.A. \\ ${ }^{3}$ Electric Power Board, Chattanooga, TN, U.S.A. \\ *Corresponding email: newjr@ornl.gov
}

\begin{abstract}
Maintaining electrical generation assets to meet peak demand increases the cost of providing electricity to a country's buildings and insufficient assets can result in power outages. In order to keep reliable electricity costs low for consumers and demand charges low for utilities, there exist markets and financial incentives for limiting consumption during peak demand.

The team has partnered with an electrical distributor servicing a $1,390 \mathrm{~km}^{2}$ area and 178,368 buildings with the aim of using urban-scale building energy modelling to inform business decisions necessary for the operation of their electric grid. A suite of software has been developed that allows the scalable creation of a "digital twin" for all buildings in the utility's service area. This virtual utility area is analysed for targeted deployment of new technologies or policies to assess building-specific savings, effects on critically-loaded grid infrastructure (e.g. feeders, substations), and aggregated impact to utility-scale operations.

This work leverages 15-minute data from each building to compare actual and simulated monthly peak-hour demand and assessment of the load factor for each building. Findings include market characterization via clustering of relative energy use profiles for $\sim 180,000$ buildings as well as simulation-informed savings opportunities indicating residential load factors of 0.17 , commercial load factors of 0.2-0.4 depending on year of construction, and general load factors of 0.16-0.5 depending on building type.
\end{abstract}

\section{Introduction}

The U.S. Department of Energy has established resiliency of critical infrastructure (i.e. the electric grid) as the top priority for the Office of Electricity with a synergistic Grid-interactive Efficient Buildings (GEB) initiative [1] by the Building Technologies Office which extends energy efficiency of buildings to understanding time-ofuse grid impacts.

As buildings become more energy efficient and with the increasing proliferation of decentralized renewable generation, many utilities are seeing an erosion of revenue per customer and actively looking to evolve the traditional utility business model. The challenge of balancing regulatory requirements between supply and demand is becoming more difficult and costly as indicated by the trend of the "duck curve" [2][3]. By capturing the more difficult, time-varying aspect of energy use to reduce peak demand, typically defined by the utility's hour of maximum energy use each calendar month, the value of time-varying energy efficiency [4] can be captured. Indeed, the growing ubiquity of smart, communicationenabled devices has enabled energy use to be grid-aware and responsive through cost-effective sensing and control. Energy efficiency (EE) and demand response (DR) may or may not work together in buildings. Nemtzow's decennial Green Effect meta-review of 100 DR programs showed $20 \%$ EE gains to a $5 \% \mathrm{EE}$ loss as a function of DR [5]. Other work shows an $8.8 \%$ peak cut with $13.3 \%$ increase in energy consumption for residential HVAC equipment [6]. Preliminary results [7] from the authors' work seems to indicate EE gains can vary from $-25 \%$ to $+27 \%$ by building type as a function of a DR measure.

\section{Background}

The Electric Power Board of Chattanooga, TN (EPB) has deployed advanced metering infrastructure (AMI) and securely shared 15-minute whole-building electrical consumption for over 150,000 buildings with Oak Ridge National Laboratory (ORNL). EPB's electrical distribution network is backed by gigabit ethernet for utility-based smart grid operations [8], allowing it to function as a high-fidelity, utility-scale living laboratory for EE and DR opportunities in the built environment.

The partnership has enabled development of a suite of software, referred to as Automatic Building detection and Energy Modeling (AutoBEM), that is: (1) able to collect cartographic, tax assessors, imagery (aerial- and streetlevel), elevation, and other data sources from multiple locations; (2) process that data with computer vision, quality assurance, and related algorithms to extract building-specific features; (3) automatically combine those features to create OpenStudio and EnergyPlus building energy models of each building; (4) quickly simulate each building for large geographical areas on world-class high performance computing resources; (5) modify buildings and compare results to show impacts of new technologies or policies in terms of energy, demand, emissions, and cost; and (6) aggregate, summarize, and interactively visualize the results for any area in a way that scales from building-specific, 15-minute impacts to critically-loaded infrastructure, to the entire electrical distribution grid. This "virtual utility" of all buildings in the service area allows city-scale, building-specific 
analysis with low-cost, same-day turnaround for most what-if scenarios.

Relevant prior work includes survey and comparison matrix of 37 different building-specific data sources [9], microclimate variation of energy use [10], urban-scale energy modelling capabilities [11]-[15], long-term climate and resiliency [16][17], creation and analysis of a virtual utility [18], and assessment of BEM accuracy to actual 15-minute energy use from over 150,000 real buildings [19]. This "digital twin" of a utility has leveraged over 3 million simulations and 13TB of data to quantify \$11-35 million in savings across 9 scenarios that may be operationally refined, validated, and shared via case studies for consideration by other utilities. These 9 monetization scenarios fall under 5 use cases related to potential changes in rate structure, demand side management, emissions, energy efficiency, and comparative analysis for customers' consumption [18]. Once a robust software Measure is written, the current system requires under 7 hours to modify every building model, perform an annual simulation, visualize cost savings (see Figure 1) using wholesale or retail rate classes, analyze/aggregate electrical load changes to areas-of-interest, and store relevant data in the utility's operational business intelligence systems.

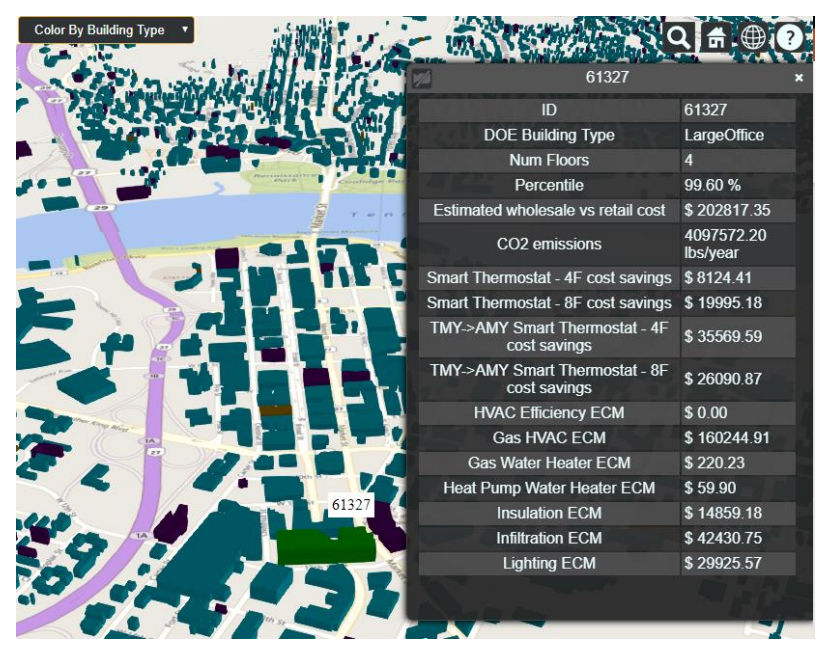

Figure 1. Utility-scale, building-specific impact can be assessed for energy, demand, emissions, and cost impacts by leveraging big data collection, HPC-enabled processing, simulation of each building, and interactive visual analytics.

\section{Methods}

\section{Clustering of actual building energy data}

Utilities are more frequently formalizing analysis related to higher-resolution AMI data. Shown in Figure 2 is an example of 2 buildings' scaled kilowatt-hour (kWh) energy pattern from midnight to midnight with data points for every 15 minutes. While a similar pattern is observed, common utility questions may include: (1) "how would we effectively visualize all customers' data for a year?" and (2) "how can we show which customers are similar in a way that is useful?"
Our team first selected time periods of interest (e.g. business hours on weekdays) to time-bin the electricity use for all buildings. We then identify relative usage patterns by applying standard normalization, resulting in each building's peak 15-minute use value as 1.0 and its lowest as 0.0 .

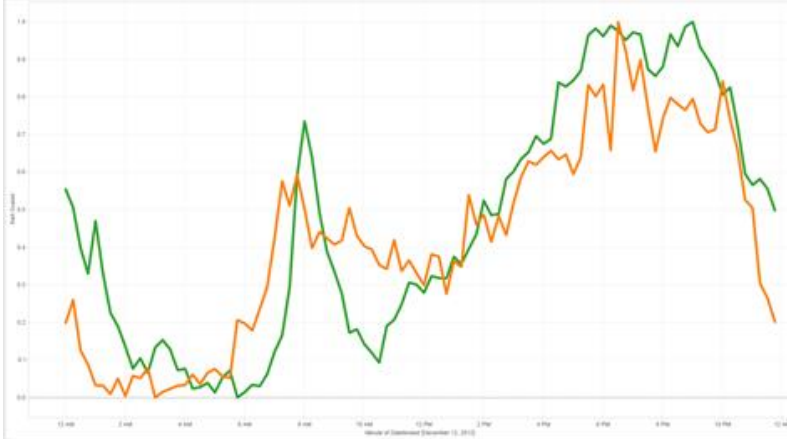

Figure 2. A plot of 24-hour energy use for two actual buildings 15-minute profiles shows similar trends that might indicate candidacy for a specific DR technology.

Clustering, via $k$-means, was used to segment all customers into significantly different load-shape patterns by minimizing the distance from each observation to the $k$ cluster centroids based on within-cluster sum squared difference by adjusted/normalized $\mathrm{kWh}$ as defined by Equation 1

$$
\underset{\mathbf{S}}{\arg \min } \sum_{i=1}^{k} \sum_{\mathbf{x} \in S_{i}}\left\|\mathbf{x}-\boldsymbol{\mu}_{i}\right\|^{2}
$$

where $\mu_{\mathrm{i}}$ is the mean of the observations, $\mathrm{x}$, assigned to cluster $S_{i}$. By clustering buildings into unique load shapes, it is anticipated that additional building characteristics relevant to marketing and niche DR applications might be made known.

\section{Analysis of simulated building energy data}

EnergyPlus [20] and OpenStudio [21] are the building physics simulation engine and middleware software development kit in which DOE has invested \$93 million since 1995. New features, better runtime performance, and creation of new prototype models of building types have recently been created from assessments of real buildings [22][23] to facilitate accurate and timely modeling of the U.S. building stock. We leverage these tools to create and simulate models of every building in the utility's service area where, due to privacy concerns, there are no internal details of the buildings directly sensed.

Quality assurance and quality control methods were previously applied to the actual 15-minute AMI data [19]. The actual annual 15-minute energy use intensity (EUI), $\mathrm{kWh}$ per building floor area, was stored in a $\sim 35,040$ element long feature vector for every building. Each building's actual profile vector was then compared against the simulated data for 3 residential vintages and every combination of the 6 vintages of 16 commercial 
building types using a dynamic 35,040-dimensional Euclidean distance.

A common metric used by utilities is "load factor," which is the ratio of the average energy use to peak demand as defined in equation 2. If a building's site DR was perfectly managed, its energy use would not vary with time and yield a load factor of 1. Conversely, a building with a load factor near 0 may have significant opportunities for DR.

$$
\text { LoadFactor }=\text { Total }(k W h) /(k W p e a k * \text { numHours })
$$

Buildings with low load factor (i.e. occasionally showing high demand) impose higher costs on an electrical system where expensive generation assets must be maintained to meet the relatively high demand. This is used as a metric to target individual buildings and flatten the utility-scale duck curve. We report results characterizing load factor by building type and vintage to promote discussion regarding unique EE and DR opportunities for specific types and vintages of a building. In ongoing work, we use simulations to assess the impact of technologies or policies on building-specific load factor and utility-scale demand charges.

\section{Results}

\section{Clustering of actual building energy data}

Using 96-dimensional k-means clustering on AMI data for different customer classes and time scales, the team was able to identify unique usage patterns that are actionable. As shown in the top row of Figure 3, our team was able to identify a typical residential trend with peaks between 5:00 and 7:00pm. This type of average daily profile from 15-minute data can help utilities identify the highest peak-hour contributors. Indeed, the 26,048 residential meters belonging to the cluster shown in the top right of Figure 3 were verified to be contributing more to the utility's demand charges and offer the greatest potential sites for demand response solutions.

In contrast to average daily profile for residential buildings, we also showcase 8 average weekly profiles for commercial buildings and the utility-relevant market segmentation this provides. Scaled $\mathrm{kWh}$ data during business hours from AMI for GSA-1, 2, and 3 buildings (i.e. small, medium, and large commercial) were clustered using Equation 1 in a way that should generalize to other utilities. These findings may help target EE and DR measures to the most relevant customers based on market segmentation by load profile. As a specific example, the grey line on the bottom-right of Figure 3 shows periods of highest activity on Sunday, Saturday, and Wednesday. Through investigation using geo-registered AMI meters and Google Street View, this cluster was verified to be composed primarily of houses of worship, a metaproperty building type not indicated elsewhere in the utility's databases and could be used to improve building energy model characteristics.
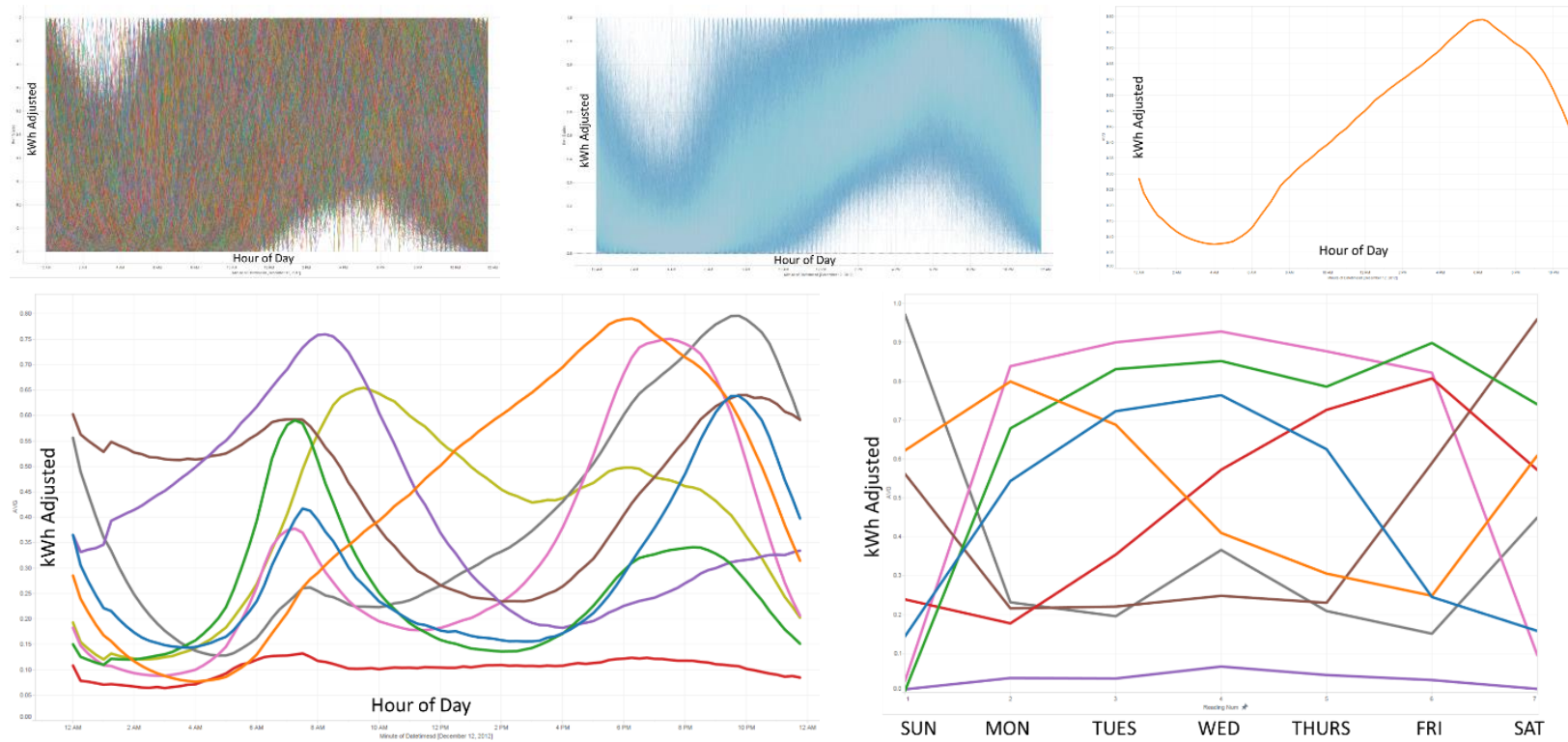

Figure 3. Actual 15-minute data from $~ 180,000$ residential customers was clustered and displayed (top left) rendered in faint blue to clarify overlap within the cluster (top middle), and identify unique load profiles, including one daily profile representing 26,048 residential meters (top right). Average daily profiles can help identify high-value buildings for demand response while average weekly profiles can facilitate market segmentation for implementation. This technique was used to identify unique daily and weekly clusters across the utility's entire area, including 9 clusters for all residential buildings during business days in Spring or Fall (bottom left) and 8 for all commercial buildings (rate classes of GSA-1,2,3) during business hours (bottom right). This market segmentation into unique daily and weekly profiles allow utilities to identify, align resources, and appropriately market relevant EE and DR services. 


\section{Analysis of simulated building energy data}

Quality assurance and quality control algorithms were applied to the actual 15-minute AMI data for all buildings with previous work showing aggregated error rates between simulated buildings and measured data [19]. For this paper, outliers were removed, resulting in a reduction from 178,368 buildings to 178,333 buildings. Using annual electricity use intensity profiles of 15-minute data for each building, building types were assigned based on closeness of match to every combination of residential and commercial building type and vintage. We then computed both actual and simulated load factors for each building. In Table 1, we anonymize by reporting only the number of each building type, the corresponding percent, and load factor for each building type after selecting only building types with a significant number of buildings.

It should be noted that while our EUI clustering technique for assigning building type shows $96 \%$ of buildings to be residential, similar to the United States average of $95 \%$, the utility's records show approximately $80 \%$ as residential. While this technique has the advantage of closely matching the measured load profiles of the real building, there is currently not sufficient data to rate its classification accuracy in terms of assigning building type. Upon further analysis, we found unusually large buildings (in terms of conditioned floor area) classified as residential, pointing toward areas for future improvement.

The load factor for residential and commercial building types has been sorted to show Outpatient as having the least potential for DR and residential buildings as having the most. In practice, however, this may be offset by the significant difference in the tractable number of targetable buildings for potential DR offerings, energy consumption, and business models relevant to these building types.

Table 1. Assigning building type based on EUI $15 \mathrm{~m}$ for buildings in Chattanooga, TN allows categorization of each building type in terms of potential for DR and improving low load factors.

\begin{tabular}{|l|r|r|r|}
\hline \multicolumn{1}{|c|}{ Building Type } & $\begin{array}{c}\text { Num } \\
\text { Bldgs }\end{array}$ & $\begin{array}{c}\text { \% of all } \\
\text { Bldgs }\end{array}$ & $\begin{array}{c}\text { Avg. } \\
\text { Load } \\
\text { Factor }\end{array}$ \\
\hline IECC Residential & 171821 & $96.35 \%$ & 0.164 \\
\hline Warehouse & 799 & $0.45 \%$ & 0.166 \\
\hline MidriseApartment & 851 & $0.48 \%$ & 0.261 \\
\hline SmallHotel & 1557 & $0.87 \%$ & 0.261 \\
\hline HighriseApartment & 2068 & $1.16 \%$ & 0.263 \\
\hline LargeHotel & 408 & $0.23 \%$ & 0.365 \\
\hline QuickServiceRest. & 318 & $0.18 \%$ & 0.380 \\
\hline Hospital & 319 & $0.18 \%$ & 0.399 \\
\hline Outpatient & 59 & $0.03 \%$ & 0.501 \\
\hline
\end{tabular}

Rather than reporting every combination of building type and vintage, the authors felt it more tractable and potentially interesting to aggregate load factor based on vintage (Table 2). With the same classification caveats described previously, this analysis indicates similar DR opportunities in residential buildings, regardless of age, whereas older commercial buildings are better than newer ones in terms of load factor.

Table 2. Residential buildings show high DR potential across vintages, but with deployment challenges for such large numbers of buildings. While older buildings typically consume more energy than newer buildings, usage profiles of newer buildings often indicate greater DR potential from a load factor perspective than older buildings.

\begin{tabular}{|c|c|c|c|c|}
\hline & Vintage & $\begin{array}{l}\text { Num } \\
\text { Bldgs }\end{array}$ & $\begin{array}{c}\% \text { of all } \\
\text { Bldgs }\end{array}$ & $\begin{array}{l}\text { Avg. Load } \\
\text { Factor }\end{array}$ \\
\hline \multirow{3}{*}{ 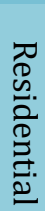 } & 2006 & 16217 & $9.1 \%$ & 0.170 \\
\hline & 2009 & 6357 & $3.6 \%$ & 0.177 \\
\hline & 2012 & 149247 & $84.0 \%$ & 0.163 \\
\hline \multirow{6}{*}{$\begin{array}{l}0 \\
0 \\
3 \\
3 \\
0 \\
0 . \\
0 \\
0\end{array}$} & Pre-1980 & 670 & $0.4 \%$ & 0.405 \\
\hline & $1980-2004$ & 1064 & $0.6 \%$ & 0.296 \\
\hline & $90.1-2004$ & 1478 & $0.8 \%$ & 0.255 \\
\hline & $90.1-2007$ & 268 & $0.2 \%$ & 0.338 \\
\hline & $90.1-2010$ & 1224 & $0.7 \%$ & 0.208 \\
\hline & $90.1-2013$ & 1808 & $1.0 \%$ & 0.256 \\
\hline
\end{tabular}

\section{Future Work}

The utility has prioritized over 30 use cases for a "virtual utility." This was used to define 9 monetization scenarios under the top 5 use cases related to: (1) potential changes in rate structure, (2) demand side management, (3) emissions, (4) energy efficiency, and (5) comparative analysis for customers' consumption to assist bill inquiries [18]. While this study supports those scenarios and use cases, detailed estimates, analysis, or summary of specific energy, demand, emissions, and monetary savings are explicitly beyond the scope of this publication but is reported in other publications currently in-review. Furthermore, recommendations for specific technologies, policies, incentive structures, or business models are subjects of potential future publications. Ongoing work is leveraging the virtual utility to analyse the roles of electrification (e.g. electric vehicle adoption and managed charging), decremental value of decentralized generation (e.g. solar), short-term weather impacts for load management, resiliency for determining placement of local storage for islandable microgrids, and long-term climate analysis for infrastructure planning at the electrical distribution scale. 


\section{Conclusion}

Actual 15-minute whole-building electrical consumption measured by revenue-grade meters from 178,368 customers has been clustered into 9 residential categories to show unique hourly and daily load profiles for U.S. homes in Chattanooga, TN. A similar analysis resulted in 8 categories for commercial buildings that allow better understanding of building-specific dynamics and marketing for energy-, demand-, emissions-, and costsaving opportunities.

Actual and scenario-based simulation of energy use at sub-hourly levels for each building is compared to utilityscale peak-hour energy use for each calendar month to quantify each building's contribution percentile to utilityscale demand during each hour of critical generation. We showcase initial results using EUI-based Euclidean distance between simulation and actual data to assign building type and report average load factor by building type and vintage to highlight the opportunities, unique challenges, and market segmentation for building energy efficiency and demand response.

\section{Acknowledgement}

This material is based upon work supported by the U.S. Department of Energy, Office of Science, and Building Technologies Office. This research used resources of the Oak Ridge National Laboratory Building Technologies Research and Integration (BTRIC), which is a DOE Office of Science User Facility. This work was funded by field work proposal CEBT105 under DOE Building Technology Office Activity Numbers BT0302000 and BT0305000. This research used resources of the Oak Ridge Leadership Computing Facility at ORNL, which is supported by the Office of Science of the DOE under Contract No. DE-AC05-00OR22725.

This manuscript has been authored by UT-Battelle, LLC, under Contract Number DEAC05-00OR22725 with DOE. The United States Government retains and the publisher, by accepting the article for publication, acknowledges that the United States Government retains a non-exclusive, paid-up, irrevocable, world-wide license to publish or reproduce the published form of this manuscript, or allow others to do so, for United States Government purposes. DOE will provide public access to these results of federally sponsored research in accordance with the DOE Public Access Plan (http://energy.gov/downloads/doe-public-access-plan).

\section{References}

[1] Nemtzow, D. (2019). Grid-interactive Efficient Buildings. [Web]

[2] Denholm, P., Margolis R., and Milford J. (2008). Production Cost Modeling for High Levels of Photovoltaics Penetration. Technical Report NREL/TP-581-42305. [PDF]

[3] California Independent System Operator Corporation (2019). Duck Curve - What the duck curve tells us about managing a green grid. Fast Facts. [PDF]
[4] Frick, N., Eckman, T., \& Goldman, C. (2017). Timevarying Value of Electric Energy Efficiency. $L B N L$ Report 2001033. [Web]

[5] Nemtzow, D., Delurey, D. \& King, C. (2007). Demand response: The Green Effect. [Web]

[6] Cole, W. J., Rhodes, J. D., Gorman, W., Perez, K. X., Webber, M. E., \& Edgar, T. F. (2014). Communityscale residential air conditioning control for effective grid management. Applied Energy, 130, 428-436. [DOI]

[7] New, J.R., Hambrick, J., and Copeland, W.E. (2017). Assessment of Value Propositions for Virtual Utility Districts: Case Study for the Electric Power Board of Chattanooga, TN. ORNL Internal Report ORNL/TM$2017 / 512$.

[8] Starke, M., Ollis, B., Glass, J., Melin, A., Liu, G. \& Sharma, I. (2017). Analysis of Electric Power Board of Chattanooga Smart Grid Investment..ORNL Internal Report ORNL/TM-2017/246. [PDF]

[9] Yuan, J., New, J.R., Sanyal, J., \& Omitaomu, O. (2015). Urban Search Data Sources. ORNL internal report ORNL/TM-2015/397.

[10] Rose, A., Allen, M., Omitaomu, O., Yuan, J., New, J.R., Branstetter, M. \& Wilbanks, T. (2016). Modeling Urban Energy Savings Scenarios using Earth System Microclimate and Urban Morphology. Urban Dynamics Institute. [Poster]

[11] Brown, J., Allen, M., Scheer, D. \& New, J.R. (2016). Seminar 56 - Data Sources toward Urban-Scale Energy Modeling, Part 2. ASHRAE Annual Conference. [GATech] [ORNL] [Autodesk]

[12] Allen, M., Bobker, M., Khan, H., Crawley, D. \& New, J.R. (2017). Seminar 55 - Urban-Scale Energy Modeling, Part 4. ASHRAE Winter Conference. [ORNL] [CUNY] [ICF] [Bentley]

[13] New, J.R., Chen, Y., Choi, J., and Bass A. (2017). Seminar 28 - Urban-Scale Energy Modeling, Part 5. ASHRAE Annual Conference. [ORNL] [LBNL] [USC]

[14] New, J.R. (2018). "TEDergy Talk: Automatic Building Energy Modeling (AutoBEM)." Building Performance Analysis Conference and SimBuild. [PDF] [PPT]

[15] Luo, X., Macumber, D., New, J.R. \& Judkoff, R. (2018). Multiscale Building Energy Modeling, Part 10. ASHRAE Winter Conference. [ORNL]

[16] Kumar, J., Hoffman, F.M., New, J.R. \& Sanyal, J. (2014). Reimagining Climate Zones for Energy Efficient Building Codes. ASHRAE Annual Conference. [PPT]

[17] New, J.R. (2018). Potential Impacts of Climate Change on the Built Environment and Urban Microclimates. ASHRAE Winter Conference. [PPT]

[18] New, J.R., Adams, M., Im, P., Yang, H., Hambrick, J., Copeland, W., Bruce, L. \& Ingraham, J.A. (2018). Automatic Building Energy Model Creation (AutoBEM) for UrbanScale Energy Modeling and Assessment of 
Value Propositions for Electric Utilities. International Conference on Energy Engineering and Smart Grids (ESG). [PDF] [PPT]

[19] Garrison, E., New, J.R., and Adams, M. (2019). Accuracy of a Crude Approach to Urban MultiScale Building Energy Models Compared to 15-min Electricity Use. ASHRAE Winter Conference. [PDF] [PPT]

[20] U.S. Dept. of Energy (2011). DOE releases new version of EnergyPlus modeling software. [Web] [source]
[21] Roth, A., Brackney, L, Parker, A. \& Beitel, A. (2016). OpenStudio: A Platform for Ex Ante Incentive Programs. [ $\underline{\mathrm{PDF}}$ [ [Web] [source]

[22] Malhotra, M., New, J.R. \& Im, P. (2018). Prototype Courthouse Building Energy Model: Building and System Characteristics. ORNL internal report ORNL/TM-2017/2. [PDF]

[23] Goel, S. et al. (2014). Enhancements to ASHRAE Standard 90.1 Prototype Building Models. PNNL Internal Report PNNL-23269. [PDF] [website] 